\title{
Problemas Potenciales que Enfrenta la Industria de Viveros en los Estados Unidos ${ }^{1}$
}

Edward A. Evans ${ }^{2}$

\section{Perspectiva de la Industria de Viveros en los Estados Unidos}

Este articulo se concentra en el posible impacto que tendría el libre comercio en la industria de viveros de los Estados Unidos. Los cultivos de viveros incluyen plantas ornamentales y árboles con tallos de madera (perennes de hoja ancha, coniferas perennes, árboles caducifolios de sombra, árboles caducifolios para flores, arbustos caducifolios y otros ornamentales), plantas de fruto o nueces para jardín, árboles que se cortan para navidad y material de propagación.

El valor de los cultivos de vivero en el campo se estiman en US\$8.92 millones (USDA, 2003).

Aunque el valor es US\$10 millones menor que el del año anterior, el crecimiento anual entre 1989 y 2002 permanece a un impresionante 4.4 por ciento. El crecimiento lento en el 2002 fue debido a que la economa en los Estados Unidos fue débil. Debido a que estas plantas generalmente se utilizan en los mercados locales, los patrones de consumo reflejaron los de producción, creciendo de US $\$ 5.4$ millones en 1989 a US\$9.1 millones en 2002.
El valor de los cultivos de vivero importados se incrementó más de dos veces entre 1989 y 2002, creciendo de US\$140 millones a $\$ 300$ millones (productos principalmente de Canada y Holanda). Sin embargo, como fracción del consumo doméstico permaneció insignificante, creciendo del 2.7 por ciento en 1989 al 3.4 porciento en el 2002 (Cuadro 1). Esta fracción relativamente pequeña entre importaciones y consumo doméstico refleja una política de regulación estricta. La porción de exportaciones relativa a la producción doméstica se mantuvo baja durante el mismo periodo, al 1.5 por ciento.

\section{El Dilema al que se Enfreta la Industria de Viveros}

Basado en evaluaciones llevadas a cabo por agencias independientes, la industria de viveros de los Estados Unidos es una de las primeras en el mundo (Kreith and Golino, 2003). El material limpio de la industria ha sido atribuido principalmente a la política estricta de importaciones basado en leyes federales de cuarentena de los Estados Unidos, bajo el Acta de Cuarentena de 1912 (revocada en el 2000),

1. Este documento, FE529, es uno de una serie de publicaciones del Departamento de Food and Resource Economics, Servicio de Extensión Cooperativa de la Florida, Instituto de Alimentos y Ciencias Agrícolas, Universidad de la Florida. (UF/IUFAS). Fecha de primera publicación: February 7, 2005. Visite nuestro sitio web EDIS en 〈http://edis.ifas.ufl.edu〉.

2. Edward A. Evans, Assistant Professor, Department of Food and Resource Economics, Tropical Research and Education Center, Homestead, FL, Florida Cooperative Extension Service, Institute of Food and Agricultural Sciences, University of Florida, Gainesville, FL.

EI Instituto de Alimentos y Ciencias Agrícolas es Un empleador que opera bajo Acción Afirmativa y provee Oportunidades Igualitarias, dedicado a promocionar la investigación, a información educativa y otros servicios, únicamente a los individuos e instituciones que operan bajo discriminación sin considerar color, raza, sexo, edad, incapacidad u origen. Para más información sobre como obtener otras publicaciones de la extensión, comuníquese con la oficina de Servicio de Extensión de su condado. Servicio de Extensión de la Florida / Instituto de Alimentos y Ciencias Agrícolas / Universidad de la Florida / Christine Taylor Waddill, Decana. 
y a una serie de programas estatales de certificación voluntaria. Para entrar a los Estados Unidos, material de viveros extranjeros debe venir de lugares con programas de certificación de virus similares a los programas en los Estados Unidos o de lo contrario deben ser examinados para ver si tienen patógenos exóticos o domésticos. Estas restricciones han disminuido las importaciones de materiales para vivero y han reducido el potencial para la introduccción accidental o intencional de patógenos dañinos. De esta manera, las restricciones son un método eficiente de controlar las enfermedades. Ellas también ayudan a minimizar los gastos del gobierno y por ende para los que pagan impuestos.

Sin embargo, cambios en la manera en que la industria opera pueden surgir debido a obligaciones con tratados internacionales, particularmente el acuerdo Sanitario y Fitosanitario (SF) de la Oganización Mundial del Comercio (OMC), el Tratado de Libre Comercio de America del Norte (TLCAN) y los propuestos Tratados de Areas de Libre Comercio de las Américas (TALCA). El problema es que las restricciones actuales no son consideradas consistentes con los principios generales del acuerdo SF de la OMC de no discriminación entre productos extranjeros y domésticos. Para corregir esta situación, los Estados Unidos canceló el Acta de Cuarentena de Plantas de 1912 y la reemplazó con el Acta de Protección de Plantas del 2000, el cual refleja mejor las disposiciones del acuerdo Sanitario y Fitosanitario de la Organización Mundial del Comercio.

Información sobre estos acuerdos se puede conseguir en las páginas de la internet de la OMC: http://www.wto.org/spanish/tratop_s/sps_s/ spsund_s.htm.

$\mathrm{El}$ acuerdo SF de la OMC reconoce la Convención Internacional de Protección de Plantas (CIPP) como la organizacion internacional que se encargará de imponer medidas internacionales que ayuden a que las regulaciones fitosanitarias no se usen como barreras injustificadas de comercio (http://www.ippc.int/IPP/En/default.htm). El tópic específico de este articulo es ver cómo la CIPP fija las reglas que gobiernan la regulación de pestes y enfermedades bajo el componente del acuerdo fitosanitario. La regla permite regulaciones solamente contra pestes dañinas que se sabe que no ocurren en el país importador o cuando la peste esta incluída en un programa oficial de control o erradicación (Foster, 2000). Consequentemente, la cuarentena federal de los Estados Unidos que restrinja la entreda de pestes que ya están presentes en los Estados Unidos o que han sido controladas o erradicadas es considerada discriminatoria contra productores extranjeros, independientemente de la magnitud de los daños económicos que la peste pueda causar. Por lo tanto, el enfoque de la CIPP elimina efectivamente, de la presente lista de patógenos regulados en los Estados Unidos, una serie de pestes para las cuales no hay programas oficiales de erradicación o control. Esta serie de pestes incluye algunos de los patógenos más dañinos que afectaron la industria de viveros, incluyendo la tristeza, exocortis y la psorosis de los ctricos; degeneración infecciosa (fanleaf), enrrollamiento de las hojas (leafroll), acorchamiento de la corteza (corky bark) y hendidura de las ramas (stem pitting) en la vid; arruga o rizadura verde (green crinkle), aplastamiento de las ramas (flat limb), gomosis (rubbery wood) y ampolla de la corteza (blister bark) en la manzana, hoyitos petreos (stony pit) y ampollas cancerosas (blister canker) en las peras; enananismo del cerezo (little cherry), manchas necróticas anulares (necrotic ringspot), enanismo del ciruelo (prune dwarf) y enfermedades-X (X-disease) en las frutas de hueso y el corazón rojo de la fresa (red stele) [Foster, 2000]. Permitir la posibilidad de que estas pestes sean importadas con los materiales de viveros podría poner en peligro la categoría de limpieza que posee la industria de viveros de los Estados Unidos.

\section{Implicaciones para la Industria de Viveros de los Estados Unidos}

Foster (2000) señala que la implicación obvia es que por cada peste doméstica en la lista de pestes excluidas se tendrá que tomar la decisión de implementar un programa de control o se tendrá que remover la peste de la lista. Cualquiera de las decisiones puede resultar costosa. Aúnmás, muchas de estas pestes domésticas están cerca de ser erradicadas o significantemente controladas, gracias a la labor de los científicos. En estos casos, implementar programas oficiales de erradicación no 
estaría justificado. Sin embargo, remover el nombre de estas pestes de la lista restringida permítíría la entrada de materiales de plantación infectados a los Estados Unidos permitiendo la resurgencia de estos patógenos lo que significaría socavar severamente la inversión y el trabajo científico de muchos años.

En el pasado, países deseando exportar material de vivero a los Estados Unidos debían tener un programa de certificación similar al de los Estados Unidos. Con la adopción del Acta de Protección de Plantas del 2000, certificación es sólo requerida para: (1) pestes extranjeras que no estén presentes en los Estados Unidos y que han sido declaradas de importancia y (2) pestes domésticas en programas oficiales de control que están implementados. Esto quiere decir que muchas pestes serán removidas de la lista de exclusión y las condiciones de entrada para estas pestes se harán más fáciles. Es concebible que esto abra una gran puerta para la entrada de pestes nuevas y más virulentas de las que se tenían reguladas en el sistema anterior.

Debido a que solo una cantidad limitada de material de plantación fue importada a los Estados Unidos bajo el Acta de Cuarentena de 1912, no hubo necesidad de mantener una infraestructura elaborada de regulación para la importación de cultivos de vivero. Sin embargo, con la inundación de materiales de vivero que se espera que venga bajo el Acta de Protección de Plantas 2000, se necesitará una infraestructura regulatoria adicional. Establecer y mantener semejante estructura tendrá implicaciones presupuestarias.

$\mathrm{El}$ acuerdo SF de la OMC, que requiere evidencia cientfica como prueba antes de que se restrinjan las importaciones, assume que "no hay riesgo en lo desconocido". Sin embargo, según las condiciones de entrada se hagan más fáciles y los Estados Unidos empiece a comerciar materiales de vivero y propagación con importadores no tradicionales, las posibilidades que se introduzcan nuevas pestes y enfermedades en los Estados Unidos se incrementarán. Especies invasivas no son necessariamente pestes en sus lugares de origen debido a la presencia de parásitos y depredadores que los mantienen en balance, pero causan daños significativoss a sistemas agrícolas, plantas y animales nativos cuando son introducidas a nuevos ambientes. Aúnmás, debido a que muchas de estas enfermedades no son detectadas inmediatamente, las ganancias a corto plazo debido al incremento libre comercio serían contrarrestadas grandemente.

Una posible solución que ha sido sugerida es la de certificación obligatorio federal o estatal para los cultivos de vivero. Dicha acción podría satisfacer el principio de no discriminación del acuerdo SF de la OMC contra productos extranjeros y al mismo tiempo preservar la lista de pestes reguladas. Sin embargo, no está claro la manera cómo este sistema funcionaría por que los Estados Unidos no tiene un programa modelo obligatorio federal en este momento (Kreith and Golino, 2003). También es posible que algunos dueños de viveros consideren la idea indeseada. Además, para enforzar programas obligatorios se requiere fondos adicionales que son mucho mayores de los que se disponen en el sistema presente.

\section{Observaciones Finales}

El acuerdo SF de la OMC reconoce la importancia de que cada país proteja sus recursos y no tiene duda de que el libre comercio materializará nuevos beneficios para cada país. Sin embargo, cuando se comercia con organismos vivos, particularmente cuando dichos organismos no son destinados para la alimentación, la asución básica de conocimiento perfecto no se realiza y el potencial para las ganacias debido al comercio es dudoso. Organismos vivos se reproducen y pueden escapar convirtiéndose en especie invasiva, causando daños al medio ambiente. Estos organismos también pueden esconder patógenos dañinos que no son detectados con facilidad y por lo tanto pasaría mucho tiempo antes de que se reconozca el daño.

\section{Referencias}

Foster, J.A. 2000. Free Trade and the American Fruit Industry. http://fpms.ucdavis.edu/FreeTradeArticleJAFoster.pdf 
Kreith, M., and D. Golino. 2003. Regulatory

Framework and Institutional Players. In Exotic Pests

Diseases Biology and Economics for Biosecurity, edited by D. Sumner. Ames, IA: Iowa State Press.

USDA. 2003. Floriculture and Nursery Crops Situation and Outlook Yearbook. FLO-2003. Market Trade Economics Division, Economic Research Service, United States Department of Agriculture, Washington, D.C. (Junio). 
Cuadro 1. Cultivos de vivero en los Estados Unidos: valor de al producción, comercio y consumo, 1989-2002.

\begin{tabular}{|c|c|c|c|c|c|}
\hline \multirow[t]{2}{*}{ Año } & Producción & Consumo & Importación & Exportación & \multirow{2}{*}{$\begin{array}{c}\text { Fracción de las } \\
\text { Importaciones } \\
(\%)\end{array}$} \\
\hline & \multicolumn{4}{|c|}{ (millones de dolars) } & \\
\hline 1989 & 5,329 & 5,393 & 143 & 79 & 2.7 \\
\hline 1990 & 5,963 & 6,018 & 157 & 102 & 2.6 \\
\hline 1991 & 6,182 & 6,241 & 166 & 107 & 2.7 \\
\hline 1992 & 6,270 & 6,332 & 182 & 120 & 2.9 \\
\hline 1993 & 6,325 & 6,373 & 192 & 143 & 3.0 \\
\hline 1994 & 6,607 & 6,658 & 203 & 152 & 3.1 \\
\hline 1995 & 7,007 & 7,109 & 240 & 138 & 3.4 \\
\hline 1996 & 7,422 & 7,549 & 255 & 129 & 3.4 \\
\hline 1997 & 7,981 & 8,099 & 264 & 146 & 3.3 \\
\hline 1998 & 8,101 & 8,217 & 287 & 171 & 3.5 \\
\hline 1999 & 8,524 & 8,668 & 301 & 156 & 3.5 \\
\hline 2000 & 8,561 & 8,724 & 307 & 144 & 3.5 \\
\hline 2001 & 8,927 & 9,095 & 312 & 144 & 3.4 \\
\hline 2002 & 8,917 & 9,076 & 298 & 137 & 3.4 \\
\hline
\end{tabular}

